\title{
Propagación in vitro de plantas adultas de Vaccinium meridionale (Ericaceae)
}

\author{
Leidy Yanira Rache Cardenal ${ }^{1,2}$ y José Constantino Pacheco Maldonado ${ }^{1}$
}

Recebido em 3/08/2009. Aceito em 8/12/2010

RESUMEN - (Propagación in vitro de plantas adultas de Vaccinium meridionale (Ericaceae)).Se desarrolló un procedimiento de micropropagación de plantas adultas de Vaccinium meridionale utilizando como explantes primarios ápices caulinares. Durante la fase de establecimiento in vitro de explantes se estudió el efecto de los medios MS/3, WPM, AND y el propuesto por Kyte para Blueberry, suplementados con 2-iP más AIA ó BA más AIA. Durante la proliferación de microtallos se evaluó el efecto del medio MS/3 líquido, sólido y en doble fase (una fase líquida sobre una fase solidificada con agar), suplementados con 2-iP más AIA. El enraizamiento in vitro y ex vitro de microtallos y macollas se indujo utilizando auxinas y/o carbón activado y para el desarrollo de raíces se utilizó un sustrato enriquecido con materia orgánica. El endurecimiento de plántulas se realizó de manera simultánea con el proceso de desarrollo radical. Después de la fase de establecimiento, la media más alta, 4.5, yemas axilares desarrolladas por explante viable, se cuantificó en MS/3 suplementado con $59.05 \mu \mathrm{M}$ de 2-iP más $17.13 \mu \mathrm{M}$ de AIA. Durante la fase de proliferación de microtallos la media más alta, 7.25, se cuantificó en MS/3 en doble fase. Después de 60 días de endurecimiento el $88-100 \%$ de los microtallos enraizaron y reactivaron su crecimiento.

Palabras claves: Bilberry colombiana, micropropagación, cultivo in vitro, ápices caulinares

\begin{abstract}
In vitro propagation of mature plants of Vaccinium meridionale (Ericaceae)). Using stem apex as primary explants, a micropropagation protocol of Vaccinium meridionale was established. During establishment phase the effect of the MS/3, WPM, AND and Kyte media, supplemented with 2-iP plus IAA or BA plus IAA was studied. During microshoot proliferation the effect of MS/3 liquid, solid and double phase (the liquid phase in a solidified phase with agar) supplemented with 2-iP plus IAA was evaluated. In vitro and ex vitro rooting of microshoots and microshoots was accomplished using auxines and/or activated charcoal; for root development a substratum with abundant organic matter was utilized. Plantlet hardening was achived simultaneously with the radical development process. After establishment phase, the highest quantity of axillary buds/explant was quantified in cultures performed in MS/3 supplemented with 2-iP, $59.05 \mu \mathrm{M}$ plus IAA $17.13 \mu \mathrm{M}$. During the microshoot proliferation phase the highest average production was obtained in double phase MS/3. After 60 days of hardening $88-100 \%$ of rooted microshoots was obtained; these plantlets showed growth reactivation.
\end{abstract}

Key words: Vaccinium meridionale, Colombian Bilberry, micropropagation, in vitro culture, shoot tips

\section{Introducción}

Vaccinium meridionale Sw. conocido en Colombia como agraz, pertenece a la familia Ericaceae y se encuentra muy frecuente de forma silvestre; es una especie promisoria de gran interés debido a que sus frutos son una fuente importante de azúcares, antioxidantes, vitaminas del complejo B y C y minerales como potasio, calcio, y fósforo (Vallejo 2000; Magnitskiy \& Ligarreto 2007; Arjona 2001; Ávila et al. 2007; Warnert 1999). Los frutos también se usan para elaborar jugos, mermeladas, dulces, flanes, tortas, helados $y$ vinos y con fines medicinales relacionados con el control de diabetes y de problemas digestivos (Echeverri 2003). Las plantas son utilizadas como fuente de leña para cocción de alimentos y de follaje para uso en floristería; la madera se usa para elaboración de muebles. Es una especie fundamental en procesos de restauración y recuperación de suelos (Echeverri 2003). El agraz se encuentra amenazado principalmente por la deforestación, fragmentación de ecosistemas, por prácticas inadecuadas durante la recolección y sobrecosecha, explotación de tierra de capote, tala de árboles y sobre explotación de las ramas para uso en floristería.

El agraz presenta dificultades para su reproducción sexual y asexual; a pesar de que los frutos contienen un gran número de semillas, los procesos de germinación y desarrollo de plantas son largos y la cantidad de plántulas viables es baja (Baskin et al. 2000). La propagación asexual mediante estacas y acodos muestra resultados poco satisfactorios, debido a los bajos porcentajes de enraizamiento (Vallejo 2000; Magnitskiy \& Ligarreto 2007; León 2001).

Vaccinium meridionale es una especie poco estudiada; se conocen algunos reportes relacionados con su distribución (Valencia \& Becerra 1995), comercialización (Vallejo 2000; Magnitskiy \& Ligarreto 2007), algunas generalidades y germinación de semillas (Valencia 1993; Magnitskiy \& Ligarreto 2007), caracterización fisicoquímica y organoléptica de frutos (Ávila et al. 2007) y reproducción asexual (Vallejo 2000; Magnitskiy \& Ligarreto 2007). Sin embargo, no se han realizado estudios in vitro en esta especie. Teniendo en cuenta que existe una gran demanda y un bajo nivel de oferta de frutos (Ávila et al. 2007) y que los métodos convencionales de propagación no permiten la obtención de cantidades suficientes de materiales vegetativos para el establecimiento de huertos comerciales, en este trabajo se establece un protocolo para la micropropagación de materiales adultos seleccionados de Vaccinium meridionale, como una alternativa efectiva para la propagación clonal de esta especie.

\section{Materiales y métodos}

Este trabajo se realizó en el Laboratorio de Cultivo de Tejidos Vegetales -BIOPLASMA- de la Escuela de Ciencias Biológicas de la Universidad Pedagógica y Tecnológica de Colombia, Tunja.

\footnotetext{
1 Universidad Pedagógica y Tecnológica de Colombia. Facultad de Ciencias, Escuela de Ciencias Biológicas, Laboratorio BIOPLASMA, Tunja, Boyacá, Colombia

2 Autor para correspondencia: leidyrache@yahoo.com
} 
Localización, selección y establecimiento de material vegetal - Las plantas adultas utilizadas como fuente de propágulos para establecimiento en invernadero y posterior cultivo in vitro, se seleccionaron en huertos silvestres localizados en el municipio de Tinjacá - Boyacá. De estas plantas se tomaron rizomas (junto con el suelo acompañante) y se plantaron en condiciones de invernadero.Durante el tiempo de experimentación, los brotes que desarrollaron los rizomas se asperjaron semanalmente con una solución de $2 \mathrm{~g} \cdot \mathrm{L}^{-1}$ de Benlate ${ }^{\circledR}$ más $2 \mathrm{~g} \cdot \mathrm{L}^{-1}$ de Antracol $^{\circledR}$.

\section{Cultivo in vitro de explantes primarios}

Fase de establecimiento - De las plantas desarrolladas en invernadero (Fig. 2A), se tomaron ápices caulinares de 2,0 - 5,0 cm de longitud (Fig. 2B) y, en cámara de flujo laminar, se sometieron al siguiente procedimiento de asepsia superficial: un enjuague con agua destilada más Tween $20(0,1 \% \mathrm{v} / \mathrm{v})$ durante 5 minutos con agitación continua; inmersión en $\mathrm{CaOCl}_{2}$ al $7 \%(\mathrm{p} / \mathrm{v})$ durante 20 minutos; tres enjuagues consecutivos con agua destilada estéril durante 5 minutos cada uno. Finalmente, los ápices se mantuvieron hasta su cultivo, en una solución de 100 $\mathrm{mg} \cdot \mathrm{L}^{-1}$ de ácido cítrico más $100 \mathrm{mg} \cdot \mathrm{L}^{-1}$ de ácido ascórbico esterilizada por filtración. Antes de la siembra en medio de cultivo, a los ápices caulinares asépticos se les eliminó las hojas (Fig. 2C) y se fraccionaron en segmentos de 2,0 cm; cada segmento se cultivó individualmente en posición horizontal, durante 45 días. En cada tratamiento se cultivaron 30 segmentos caulinares.

En esta fase se evaluó el efecto de los medios de cultivo indicados en la Tab. 1. Cada uno de los cuatro medios se suplementó con 2-iP (2-isopenteniladenina) más AIA (Ácido 3-indolacético, esterilizado por filtración) ó con BA $\left(\mathrm{N}^{6}-\right.$ Benciladenina) más AIA. Los tratamientos ensayados fueron: Medio WPM + 59,05 $\mu \mathrm{M} 2 \mathrm{iP}$ (T1); WPM +13,3 $\mu \mathrm{M}$ BA (T2); KYTE + 59,05 $\mu \mathrm{M} 2 \mathrm{iP}(\mathrm{T} 3) ; \mathrm{KYTE}+13,3$ $\mu \mathrm{M}$ BA (T4); ANDERSON (AND) + 59,05 $\mu \mathrm{M} 2 \mathrm{iP}$ (T5); ANDERSON $+13,3 \mu \mathrm{M}$ BA (T6); MS $+59,05 \mu \mathrm{M} 2 \mathrm{iP}$ (T7); MS $+13,3 \mu \mathrm{M}$ BA (T8). Cada uno de los tratamientos se suplementó con 17,13 $\mu \mathrm{M}$ AIA. Al finalizar esta etapa (después de 45 días de cultivo) se evaluó el efecto de los medios de cultivo sobre: número de explantes viables, desarrollo de yemas axilares, e incidencia de procesos necróticos y contaminación.

Fase de proliferación - Microtallos de longitud $\geq 0,75 \mathrm{~cm}$, con 3,6 yemas axilares en promedio, desarrollados durante la fase de establecimiento, se utilizaron para los ensayos de proliferación en MS/3 sólido, líquido y doble fase (una fase líquida sobre una fase solidificada con agar, Viseur 1987), suplementados con 59,05 $\mu \mathrm{M}$ de 2-iP más 17,13 $\mu \mathrm{M}$ de AIA. Como soporte para los explantes cultivados en medio líquido se utilizaron canastillas de $4,5 \mathrm{~cm}$ de diámetro elaboradas con PVC (cloruro de polivinilo) y tela tul (Fig. 2D). La composición del medio sólido y del medio líquido en la doble fase fue la misma a excepción del agar. Después de 45 días de cultivo en cada uno de los tres medios se evaluó: número de yemas desarrolladas por explante y longitud de microtallos. En cada medio se cultivaron 30 microtallos y el ensayo se realizó por duplicado.Con el fin de estimular el proceso de elongación, microtallos y macollas producidos en los medios de proliferación se subcultivaron en MS/3 sin reguladores de crecimiento y en $\mathrm{MS} / 3$ suplementado con $3 \mathrm{~g} \cdot \mathrm{L}^{-1}$ de carbón activado. En cada medio se cultivaron 30 microtallos y 30 macollas y el ensayo se realizó por duplicado. Después de 45 días de subcultivo en los medios para elongación se cuantificó la longitud de los microtallos.

Fase de enraizamiento in vitro y endurecimiento de plántulas - Para inducción de enraizamiento in vitro, microtallos (MI) de longitud $\geq 1,5 \mathrm{~cm}$ provenientes de los medios de elongación, se cultivaron en MS/ 3 suplementado con diferentes auxinas (Tab. 2, tratamientos 1 a 7) y después de 45 días de cultivo, los MI se enjuagaron con agua corriente y se transfirieron a bandejas de poliestireno $(21 \mathrm{x}$ $21 \times 5.5 \mathrm{~cm}$ ) con tierra de capote (mantillo de bosque). Las bandejas se colocaron dentro de cajas de vidrio de 50 x 30 x $10 \mathrm{~cm}$, cerradas con plástico extensible; las condiciones del ambiente interior de las cajas fueron $23^{\circ} \mathrm{C}$ y humedad relativa de $97 \%$. Las cajas se mantuvieron en cuarto de incubación y las bandejas se regaron semanalmente, por aspersión manual. Después de 60 días, el plástico extensible se eliminó de forma progresiva (durante 15 días). Posteriormente, las plántulas se transfirieron a vasos plásticos (de $100 \mathrm{~mL}$ de capacidad) con tierra de capote y se llevaron a invernadero (75-85\% de humedad relativa, temperatura media diurna $18^{\circ} \mathrm{C}$ y nocturna $12{ }^{\circ} \mathrm{C}$ ).

Fase de enraizamiento ex vitro y endurecimiento de plántulas - Para inducción de enraizamiento ex vitro, MI de longitud $\geq 1,5 \mathrm{~cm}$ y macollas (MA) con $10 \mathrm{MI}$ en promedio, de 0,7 a $2,0 \mathrm{~cm}$ de longitud, provenientes de los medios de elongación, se enjuagaron con agua corriente para eliminar el agar adherido a la base; luego, las porciones basales de los MI y las MA se trataron (aplicando pulsos de 2 minutos) con las soluciones de auxinas indicadas en la Tab. 2 (tratamientos 8 a 12). Después de los pulsos, tanto los MI como las MA se manipularon de manera semejante a los MI provenientes del medio de inducción de enraizamiento in vitro. En esta etapa se utilizaron $30 \mathrm{MI}$ y 30 MA para cada tratamiento y se cuantificó la viabilidad de plántulas, el porcentaje de MI y MA enraizados, longitud de la raíz y porcentaje de plántulas que reactivaron su crecimiento.

Condiciones generales de cultivo - El pH de todos los medios de cultivo utilizados se ajustó a 5,0 con $\mathrm{KOH}$ y/o $\mathrm{HCl}$ y se esterilizaron en autoclave a 15 psi y $121^{\circ} \mathrm{C}$ durante 20 minutos. Todos los cultivos realizados se mantuvieron en cuarto de incubación, a temperatura de $23 \pm 1^{\circ} \mathrm{C}$, con iluminación continua $\left(70-80 \mu \mathrm{mol} . \mathrm{m}^{2} / \mathrm{s}\right)$ suministrada por lámparas fluorescentes luz de día.

Para el análisis estadístico de los datos se realizó análisis de varianza (ANOVA), con un nivel de confiabilidad del 95\%. Para los factores que resultaron estadísticamente significativos se realizó la prueba LSD. Los datos fueron procesados con el paquete estadístico StatGraphic versión 4,0. 
Tabla 1. Composición de los medios de cultivo utilizados durante la etapa de establecimiento in vitro de segmentos caulinares de Vaccinium meridionale. MS: (Murashige \& Skoog 1962); MS/3: MS con macroelementos a 1/3 de la concentración original; AND: Anderson 1984 y WPM: (Woody Plant Medium, Lloyd \& Brent 1980) modificados y el medio propuesto por Kyte (1987). Datos en $\mathrm{mg} \cdot \mathrm{L}^{-1}$.

\begin{tabular}{lcccc}
\hline Componentes & AND & WPM & MS/3 & KYTE \\
\hline Macroelementos & & & 550 & 160 \\
$\mathrm{NH}_{4} \mathrm{NO}_{3}$ & 400 & 400 & - & 708 \\
$\mathrm{Ca}\left(\mathrm{NO}_{3}\right)_{2} \cdot 4 \mathrm{H}_{2} \mathrm{O}$ & - & 556 & - & 202 \\
$\mathrm{KNO}_{3}$ & 480 & 170 & 56 & 408 \\
$\mathrm{KH}_{2} \mathrm{PO}_{4}$ & - & 91 & 152 & - \\
$\mathrm{CaCl}_{2} \cdot 2 \mathrm{H}_{2} \mathrm{O}$ & 440 & 990 & - & - \\
$\mathrm{K}_{2} \mathrm{SO}_{4}$ & - & 370 & 123 & - \\
$\mathrm{MgSO}_{4} \cdot 7 \mathrm{H}_{2} \mathrm{O}$ & 370 & - & - \\
$\mathrm{NaH}_{2} \mathrm{PO}_{4} \mathrm{H}_{2} \mathrm{O}$ & 380 & & - \\
\hline
\end{tabular}

Microelementos: MS + (en mg $\left.\cdot \mathrm{L}^{-1}\right): \mathrm{FeSO}_{4} \cdot 7 \mathrm{H}_{2} \mathrm{O}: 55,6$; $\mathrm{Na}_{2}$ EDTA: 74,6; Ácido Nicotínico: 1,0; Tiamina-HCl: 1,0; Piridoxina-HCl: 1,0; Adenina: 80; Sacarosa: 20000; Ácido ascórbico: 100; Agar oxoid: 6500.

Tabla 2. Tratamientos ensayados para inducir enraizamiento in vitro y ex vitro en microtallos y macollas de Vaccinium meridionale. AIA: Ácido 3-indolacético; AIB: Ácido Indolbutírico; ANA: Ácido Naftalenacético. MI: microtallos; MA: macollas.

\begin{tabular}{|c|c|c|c|}
\hline \multicolumn{2}{|c|}{ Tratamientos } & \multirow{2}{*}{$\frac{\text { Concentración }(\mu \mathrm{M})}{22,84}$} & \multirow[t]{2}{*}{ Tipo de explante y condiciones de cultivo } \\
\hline E1 & AIA & & \\
\hline E2 & AIA & 11,42 & \multirow{6}{*}{ MI, inducción enraizamiento in vitro. } \\
\hline E3 & AIB & 24,60 & \\
\hline E4 & AIB & 73,5 & \\
\hline E5 & AIB + carbón activado & $24,6+3 \mathrm{~g} \cdot \mathrm{L}^{-1}$ & \\
\hline E6 & Carbón activado & $3 \mathrm{~g} \cdot \mathrm{L}^{-1}$ & \\
\hline E7 & Sin reguladores & & \\
\hline E8 & ANA & 5,37 & \multirow{5}{*}{$\begin{array}{c}\text { MI y MA, inducción enraizamiento ex vitro, } \\
\text { pulsos de } 2 \text { minutos. }\end{array}$} \\
\hline E9 & AIB & 4,9 & \\
\hline E10 & ANA & 32,22 & \\
\hline E11 & AIB & 29,52 & \\
\hline E12 & Sin reguladores & & \\
\hline
\end{tabular}

\section{Resultados}

Material vegetal - El tratamiento de las plantas desarrolladas y mantenidas en invernadero con la solución de Benlate ${ }^{\circledR}$ + Antracol $^{\circledR}$, fue efectivo para eliminar la mayor parte de hongos superficiales de los explantes primarios. Cuando las plantas no fueron asperjadas, el porcentaje de explantes contaminados alcanzó $80-100 \%$, mientras que cuando las plantas se asperjaron dicho porcentaje disminuyó hasta $20 \%$. Etapa de establecimiento - Durante esta etapa se evidenció un aumento progresivo del porcentaje de explantes necróticos a medida que transcurrió el tiempo de cultivo; cuantificándose los mayores porcentajes, $70 \%$, en los explantes cultivados en WPM y Anderson suplementados con 59,05 $\mu \mathrm{M}$ de 2-iP más 17,13 $\mu \mathrm{M}$ de AIA(Fig. 1, T1 y T5); los porcentajes más bajos, 10 y $20 \%$, se cuantificaron en MS/3 con 2-iP más AIA y BA más AIA (T7 y T8, Fig. 1). Estos resultados muestran que los procesos de necrosis en tejidos de Vaccinium meridionale están influenciados tanto por la composición y concentración de macroelementos de los medios de cultivo como por su interacción con la citoquinina adicionada. Durante esta fase se observó que los segmentos caulinares cultivados en MS/3 con 59,05 $\mu \mathrm{M}$ de 2-iP más 17,13 $\mu \mathrm{M}$ de AIA(T7), expresaron una considerable capacidad para reactivar y desarrollar yemas axilares (Tab. 3), cuantificándose en ellos la mayor cantidad promedio de yemas reactivadas/explante, 4,5 ; mientras que en los segmentos caulinares cultivados en MS/3 y en el medio propuesto por Kyte con 13,3 $\mu \mathrm{M}$ de BA más $17,13 \mu \mathrm{M}$ de AIA (T8 y T4), se cuantificaron medias de 1,4 y 1,2 yemas reactivadas/explante viable, respectivamente. En WPM (T1) y AND (T5) suplementados con 59,05 $\mu \mathrm{M}$ de 2-iP más 17,13 $\mu \mathrm{M}$ de AIA, aunque se cuantificaron los porcentajes más altos $(70 \%)$ de explantes viables, durante 45 días de cultivo no se observó reactivación del crecimiento 


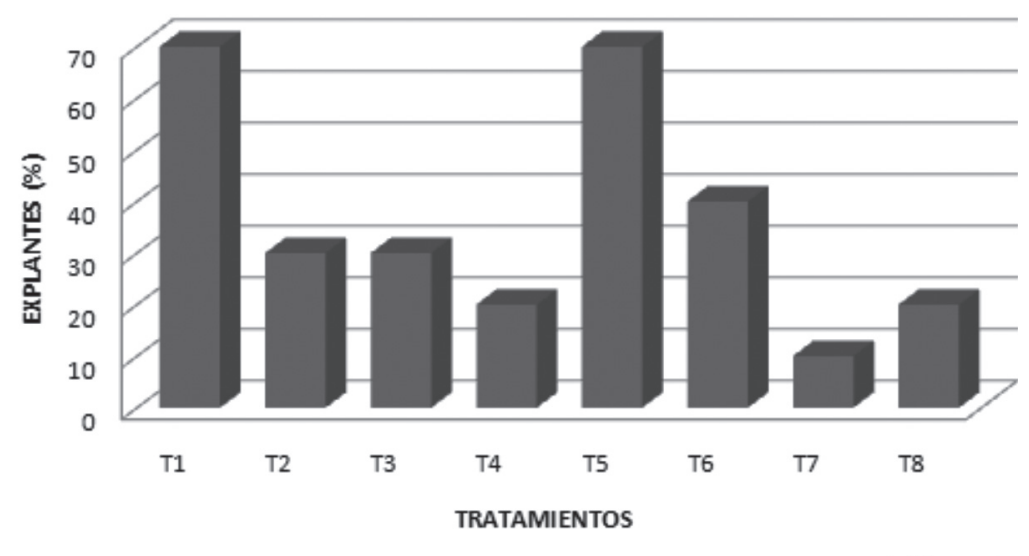

Figura 1. Necrosis de explantes primarios de Vaccinium meridionale, durante la fase de establecimiento in vitro. Medio WPM $+59,052 \mathrm{PP}+17,13 \mu \mathrm{M}$ AIA (T1); WPM+13,3 $\mu \mathrm{M}$ BA+17,13 $\mu \mathrm{M}$ AIA (T2); KYTE $+59,05 \mu \mathrm{M} 2 \mathrm{P}+17,13 \mu \mathrm{M}$ AIA (T3); KYTE $+13,3 \mu \mathrm{M}$ BA+17,13 $\mu \mathrm{M}$ AIA (T4); AND $+59,05 \mu \mathrm{M} 2 \mathrm{P}+17,13 \mu \mathrm{M}$ AIA (T5); AND+13,3 $\mu \mathrm{M}$ BA+17,13 $\mu \mathrm{M}$ AIA (T6); MS+59,05 $\mu \mathrm{M}$ 2iP+17,13 $\mu \mathrm{M}$ AIA (T7); MS +13,3 $\mu \mathrm{M}$ BA+17,13 $\mu \mathrm{M}$ AIA (T8).

de las yemas axilares (Tab. 3).

Fase de proliferación - Con base en los resultados obtenidos en la fase de establecimiento, se determinó que el medio más aconsejable para continuar multiplicando brotes in vitro era $\mathrm{MS} / 3$ suplementado con 59,05 $\mu \mathrm{M}$ de 2-iP más $17,13 \mu \mathrm{M}$ de AIA (T7). Durante la fase de proliferación, en los cultivos realizados en medio T7 sólido, líquido y doble fase, se observó que los explantes cultivados en doble fase reactivaron mayor cantidad de yemas y desarrollaron mayor número de microtallos axilares (Fig. 2E) que los explantes cultivados en los medios sólido y líquido (Fig. $2 \mathrm{~F}$ y $2 \mathrm{G}$, respectivamente). Así mismo, se cuantificó 7,25 microtallos/explante en promedio (Tab. 4), con longitud media de $0,9 \mathrm{~cm}$, en medio doble fase, seguidos por 5,91 con longitud promedio de $0,59 \mathrm{~cm}$ en medio líquido. En medio sólido se cuantificó menor media y longitud promedio de microtallos desarrollados. Los resultados obtenidos (Tab. 5; Fig. 2H), indican que el ensayo realizado para estimular la elongación de los microtallos fue efectivo, cuantificándose el mayor incremento en longitud, $\overline{\mathrm{X}}=2,54 \mathrm{~cm}$, en microtallos cultivados en $\mathrm{MS} / 3$ suplementado con $3 \mathrm{~g} \cdot \mathrm{L}^{-1}$ de carbón activado y un ligero aumento, $1,66 \mathrm{~cm}$, en microtallos cultivados en $\mathrm{MS} / 3$ sin reguladores de crecimiento.

Enraizamiento in vitro de microtallos y endurecimiento de plántulas - Durante la fase de inducción in vitro de enraizamiento, los MI cultivados en MS/3 con las diferentes auxinas y suplementos adicionados, no formaron estructuras radicales visibles; sin embargo, al final de la fase de endurecimiento, después de 50 días de transferidos los MI inducidos a tierra de capote, se cuantificó (Tab. 6) 100\% de MI enraizados en aquellos estimulados con 22,84 y 11,42 $\mu \mathrm{M}$ de AIA (E1 y E2) y con 24,60 $\mu \mathrm{M}$ de AIB más $3 \mathrm{~g} \cdot \mathrm{L}^{-1}$ de carbón activado (E5, Fig. 2I). Con respecto a longitud de raíz (Tab. 6), los valores medios más elevados, 2,9, 2,32 y 2,25 se cuantificaron en MI inducidos en presencia de 3 $\mathrm{g} \cdot \mathrm{L}^{-1}$ de carbón activado (E6), 73,5 $\mu \mathrm{M}$ de AIB (E4) y 22,84 $\mu \mathrm{M}$ de AIA (E1).

Enraizamiento ex vitro y endurecimiento de plántulas Los datos obtenidos sobre enraizamiento ex vitro de MI y MA (Fig. 2I, Tab. 7) muestran que los porcentajes más altos, 88 y $56 \%$, se cuantificaron en MI sin tratamiento de inducción rizogénica y en MI tratados con pulsos de 2 minutos con 5,37 $\mu \mathrm{M}$ de ANA, respectivamente. Así mismo, los porcentajes más altos $91,3 \%$ y $71,4 \%$ de MA enraizadas se cuantificaron en los tratamientos con pulsos de $4,90 \mu \mathrm{M}$ de AIB y 5,37 $\mu \mathrm{M}$ de ANA, respectivamente. En MI tratados con pulsos de $32,22 \mu \mathrm{M}$ de ANA (E10), sin reguladores (E12) y con $5,37 \mu \mathrm{M}$ de ANA (E8) se cuantificó $1,89,1,82$ y $1,5 \mathrm{~cm}$ de longitud media de la raíz. Sin embargo, en MA la longitud media de la raíz aumentó en casi todos los tratamientos, excepto en el E9 (4,90 $\mu \mathrm{M}$ de ANA) en el que la longitud media de la raíz fue $1,14 \mathrm{~cm}$. Aunque inducir enraizamiento ex vitro es más fácil que in vitro, solo el $58 \%$ de las plántulas enraizadas reactivaron su crecimiento en invernadero después de 90 días; mientras que induciendo enraizamiento in vitro se alcanzó $88-100 \%$ de plántulas aclimatizadas con evidente reactivación de crecimiento después de 90 días de endurecimiento (Fig. 2J 1 y 2).

\section{Discusión}

Cuando los explantes primarios proceden de plantas adultas, tanto el establecimiento de cultivos como la proliferación in vitro de microtallos son etapas difíciles de realizar en la mayoría de las especies leñosas; dicha dificultad se debe, en gran parte, al alto grado de contaminación exógena y endógena, así como la escasa reactividad in vitro de los tejidos tomados de plantas adultas de campo (Trippi 1982); al respecto, Jaakola et al. (2001) indican que la iniciación del crecimiento in vitro de explantes de Vaccinium es muy limitada cuando se utilizan plantas de campo y, según Brisette et al. (1990) y Reed \& Abdelnour (1991), la causa principal es el alto grado de contaminación. En este trabajo 

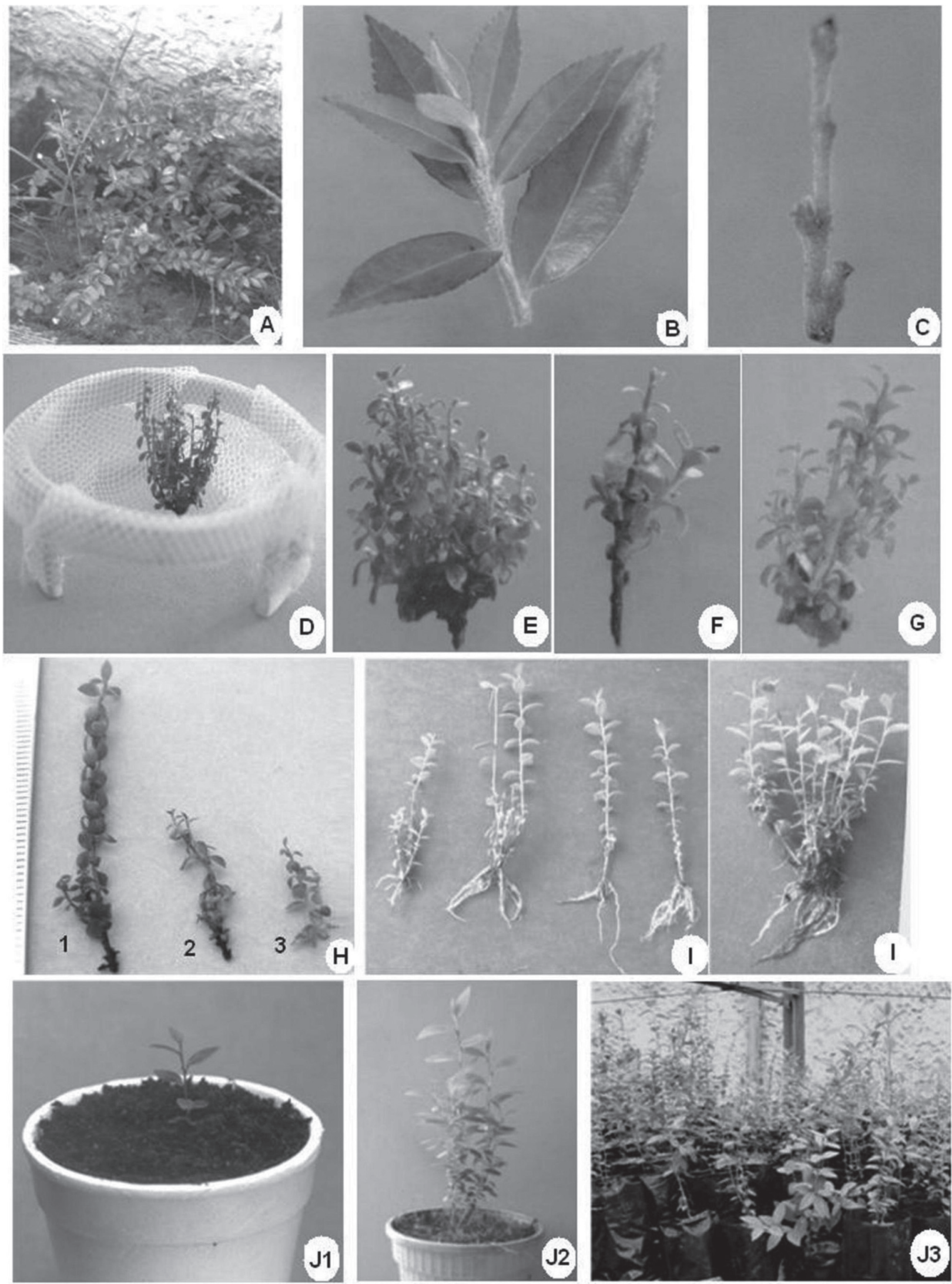

Figura 2. Micropropagación de Vaccinium meridionale A. Planta adulta, fuente de explantes primarios. B. Ápice caulinar. C. Explante primario. D. Soporte para explantes cultivados en medio líquido. E-G: Microtallos con yemas axilares en desarrollo, cultivados en MS/3 doble fase (E) en sólido (F) y líquido (G). H. Microtallos elongados en MS/3 suplementado con carbón activado (1), sin reguladores (2) y con 2-iP y AIA (3). I. Microtallos y macollas enraizados. J. Plántulas aclimatizadas después de 90 días (1 y 2) y después de 180 días. 
Tabla 3. Efecto de diferentes medios de cultivo sobre la reactivación del crecimiento de yemas axilares de segmentos caulinares de Vaccinium meridionale. Medio WPM+59,05 2iP+17,13 $\mu \mathrm{M}$ AIA (T1); WPM+13,3 $\mu \mathrm{M} \mathrm{BA}+17,13 \mu \mathrm{M}$ AIA(T2); KYTE + 59,05 $\mu \mathrm{M} 2 \mathrm{iP}+17,13 \mu \mathrm{M}$ AIA (T3); KYTE+13,3 $\mu \mathrm{M}$ BA+17,13 $\mu \mathrm{M}$ AIA (T4); AND+59,05 $\mu \mathrm{M}$ 2iP+17,13 $\mu \mathrm{M}$ AIA (T5); AND+13,3 $\mu \mathrm{M}$ BA+17,13 $\mu \mathrm{M}$ AIA (T6); MS+59,05 $\mu \mathrm{M}$ 2iP+17,13 $\mu \mathrm{M}$ AIA (T7); MS +13,3 $\mu \mathrm{M}$ BA+17,13 $\mu \mathrm{M}$ AIA (T8). EV: Explantes viables; SC: Segmento caulinar; $\bar{x} / E V$ : Promedio por explante viable; LM: Longitud de microtallos; ( $\bar{x}$ ): Promedio; \pm Desviación estándar. Promedios con una misma letra no difieren estadísticamente, según prueba $\operatorname{LSD}(P=0,05)$.

\begin{tabular}{lcccc}
\hline \multirow{2}{*}{ Tratamientos } & EV & Yemas axilares/SC & Yemas reactivadas & LM \\
& $(\%)$ & $(\overline{\mathrm{x}})$ & $\overline{\mathrm{x}} / \mathrm{EV}$ & $0,0 \pm 0,0 \mathrm{a}$ \\
\hline T1 & 70 & 4,8 & $0,6 \pm 0,89 \mathrm{~b}$ & $0,0 \pm 0,0 \mathrm{a}$ \\
T2 & 50 & 6,6 & $0,83 \pm 1,16 \mathrm{~b}$ & $1,53 \pm 0,85 \mathrm{~cd}$ \\
T3 & 60 & 4,6 & $1,2 \pm 1,09 \mathrm{~b}$ & $0,94 \pm 0,41 \mathrm{~b}$ \\
T4 & 50 & 4,2 & $0,0 \pm 0,0 \mathrm{a}$ & $1,4 \pm 0,42 \mathrm{bcd}$ \\
T5 & 70 & 3,4 & $0,66 \pm 1,03 \mathrm{~b}$ & $0,0 \pm 0,0 \mathrm{a}$ \\
T6 & 60 & 4,8 & $4,5 \pm 1,91 \mathrm{c}$ & $0,95 \pm 0,28 \mathrm{bc}$ \\
T7 & 40 & 6,0 & $1,4 \pm 1,34 \mathrm{~b}$ & $0,99 \pm 0,49 \mathrm{~b}$ \\
T8 & 50 & 6,0 & & $1,54 \pm 0,27 \mathrm{~d}$ \\
\hline
\end{tabular}

Tabla 4. Microtallos de Vaccinium meridionale desarrollados durante la fase de proliferación en medio MS/3 líquido, sólido y en doble fase suplementado con 59,05 $\mu \mathrm{M}$ de 2-iP (2-isopenteniladenina) $+17,13 \mu \mathrm{M}$ de AIA (Ácido 3-indolacético). ( $\overline{\mathrm{x}}$ ): Promedio; EP: Explante primario; \pm Desviación estándar. Promedios con una misma letra no difieren estadísticamente, según prueba LSD $(P=0,05)$.

\begin{tabular}{lccc}
\hline \multirow{2}{*}{ Medio } & Yemas/EP & \multicolumn{2}{c}{ Microtallos desarrollados } \\
& $(\overline{\mathrm{x}})$ & $\overline{\mathrm{x}}$ & Longitud $(\overline{\mathrm{x}} \mathrm{cm})$ \\
\hline Líquido & 12,1 & $5,91 \pm 4,16 \mathrm{~b}$ & $0,59 \pm 0,27 \mathrm{a}$ \\
Sólido & 9,2 & $3,0 \pm 1,65 \mathrm{a}$ & $0,49 \pm 0,32 \mathrm{a}$ \\
Doble fase & 10,3 & $7,25 \pm 2,80 \mathrm{~b}$ & $0,90 \pm 0,06 \mathrm{~b}$ \\
\hline
\end{tabular}

Tabla 5. Longitud de microtallos de Vaccinium meridionale después de la fase de elongación en diferentes medios de cultivo. ( $\bar{x})$ : Promedio; \pm Desviación estándar. MS/3: Medio Murashige \& Skoog (1962) con macroelementos a 1/3 de la concentración original; 2-iP: 2-isopenteniladenina; AIA: Ácido 3-indolacético. Promedios con una misma letra no difieren estadísticamente, según prueba LSD $(P=0,05)$.

\begin{tabular}{lc}
\hline Medio para elongación & $\begin{array}{c}\text { Longitud microtallos } \\
\end{array}$ \\
\hline $\mathrm{MS} / 3+2$-iP $(59,05 \mu \mathrm{M})+\mathrm{AIA}(17,13 \mu \mathrm{M})$ & $1,19 \pm 0,33 \mathrm{a}$ \\
$\mathrm{MS} / 3+$ Carbón Activado $\left(3 \mathrm{~g} \cdot \mathrm{L}^{-1}\right)$ & $2,54 \pm 0,71 \mathrm{c}$ \\
$\mathrm{MS} / 3$ & $1,66 \pm 0,53 \mathrm{~b}$ \\
\hline
\end{tabular}

Tabla 6. Enraizamiento in vitro de microtallos de Vaccinium meridionale. Después de 45 días de inducción in vitro de enraizamiento, los microtallos se transfirieron a tierra de capote en condiciones controladas de temperatura y humedad relativa. Después de 60 días las plántulas se llevaron a invernadero en nuevas condiciones de cultivo. AIA: Ácido 3-indolacético; AIB: Ácido Indolbutírico; CA: Carbón activado; MIE: Microtallos enraizados; ( $)$ ): Promedio; \pm Desviación estándar. Promedios con una misma letra no difieren estadísticamente, según prueba LSD $(P=0,05)$.

\begin{tabular}{lccc}
\hline & Fase de inducción enraizamiento & \multicolumn{2}{c}{ Fase de expresión } \\
Tratamiento & $(\mu \mathrm{M})$ & MIE & $\begin{array}{c}\text { Longitud raíz } \\
(\%)\end{array}$ \\
\hline E1 & AIA $(22,84)$ & 100 & $2,25 \pm 0,68 \mathrm{~b})$ \\
E2 & AIA $(11,42)$ & 100 & $2,08 \pm 0,74 \mathrm{~b}$ \\
E3 & AIB $(24,60)$ & 50 & $1,89 \pm 0,53 \mathrm{ab}$ \\
E4 & AIB $(73,5)$ & 90 & $2,32 \pm 0,48 \mathrm{bc}$ \\
E5 & AIB $(24,60)+\mathrm{CA}\left(3 \mathrm{~g} \cdot \mathrm{L}^{-1}\right)$ & 100 & $1,33 \pm 0,89 \mathrm{a}$ \\
E6 & $\mathrm{CA}\left(3 \mathrm{~g} \cdot \mathrm{L}^{-1}\right)$ & 90 & $2,9 \pm 0,75 \mathrm{c}$ \\
E7 & Sin reguladores & 88 & $1,7 \pm 0,74 \mathrm{ab}$ \\
\hline
\end{tabular}


Tabla 7. Enraizamiento ex vitro de microtallos y macollas de Vaccinium meridionale. Después de aplicar pulsos de 2 minutos con soluciones de auxinas a las porciones basales de MI y MA se cultivaron durante 45 días en tierra de capote en condiciones controladas de temperatura y humedad relativa y después de 60 días las plántulas se llevaron a invernadero en nuevas condiciones de cultivo. ANA: Ácido Naftalenacético; AIB: Ácido Indolbutírico; MIE: Microtallos enraizados; MAE: Macollas enraizadas; $(\bar{x})$ : Promedio; \pm Desviación estándar. N.S.: No significativo. Promedios con una misma letra no difieren estadísticamente, según prueba $\operatorname{LSD}(P=0,05)$.

\begin{tabular}{|c|c|c|c|c|c|}
\hline Tratamiento & $\begin{array}{l}\text { Reguladores } \\
\qquad(\mu \mathrm{M})\end{array}$ & $\begin{array}{l}\text { MIE } \\
(\%)\end{array}$ & $\begin{array}{l}\text { Longitud raíz } \\
\qquad(\overline{\mathrm{x}} \mathrm{cm})\end{array}$ & $\begin{array}{l}\text { MAE } \\
(\%)\end{array}$ & $\begin{array}{l}\text { Longitud raíz } \\
\qquad(\bar{x} \mathrm{~cm})\end{array}$ \\
\hline E8 & ANA $(5,37)$ & 56 & $1,5 \pm 0,65$ & 71,4 & $2,38 \pm 0,93 \mathrm{bc}$ \\
\hline E9 & AIB $(4,90)$ & 0 & $0,0 \pm 0,0$ & 91,3 & $1,14 \pm 0,48 \mathrm{a}$ \\
\hline E10 & ANA $(32,22)$ & 16 & $1,89 \pm 0,65$ & 46,2 & $2,93 \pm 0,54 \mathrm{c}$ \\
\hline E11 & AIB $(29,52)$ & 0 & $0,0 \pm 0,0$ & 35,3 & $2,21 \pm 0,67 b$ \\
\hline \multirow[t]{2}{*}{ E12 } & Sin reguladores & 88 & $1,82 \pm 0,82$ & 50 & $2,1 \pm 0,9 b$ \\
\hline & & & N.S. & & \\
\hline
\end{tabular}

se observó que los explantes de Vaccinium meridionale tomados de plantas de campo y cultivados in vitro sufren pardeamiento y mueren; la muerte de estos explantes se debe, en gran parte, a las drásticas condiciones de asepsia que deben ser aplicadas para eliminar los contaminantes superficiales. Además, el establecimiento de plantas adultas en invernadero y la aspersión periódica con Benlate y Antracol, permitió controlar la presencia de contaminantes fúngicos, produciendo una evidente disminución de la contaminación de explantes primarios.

Teniendo en cuenta el tipo de explante a cultivar, se han utilizado diferentes agentes desinfectantes y tiempos de exposición para establecer in vitro tejidos de diferentes especies de Vaccinium. En este trabajo se observó que el tratamiento con $\mathrm{CaOCl}_{2}$ al $7 \%(\mathrm{p} / \mathrm{v})$ durante 20 minutos permitió obtener segmentos caulinares de Vaccinium meridionale libres de contaminantes superficiales. Jaakola et al. (2001) también utilizó $\mathrm{CaOCl}_{2}$ al $6 \%$ durante 10 minutos para asepsia superficial de segmentos caulinares de Vaccinium myrtillus y Vaccinium vitis-idaea y obtuvo explantes superficialmente asépticos para establecimiento de cultivos. En otros trabajos se han utilizado diferentes productos para asepsia superficial de explantes; Debnath \& McRae (2001) utilizaron hipoclorito de sodio a $0,787 \%$ (15\% de blanqueador comercial) durante 25 minutos para asepsia de explantes tomados de plantas jóvenes de Vaccinium macrocarpon y Ostrolucká et al. (2007), utilizaron bicloruro de mercurio al $0,1 \%$, durante 6 minutos, para asepsia de microtallos con yemas dormantes tomados de plantas adultas de Vaccinium corymbosum.

Con respecto a la posición de los explantes en el medio de cultivo, se observó que la posición horizontal, respecto a la vertical, de manera evidente afectó la estimulación y desarrollo de yemas axilares. Esta respuesta se debe a que la posición horizontal de los explantes permite que las yemas axilares queden en contacto directo con los nutrientes y reguladores de crecimiento del medio de cultivo, tal como lo ha indicado Debnath (2005).
Los medios Anderson y WPM suplementados con 2-iP más AIA no facilitaron la inducción y desarrollo de yemas axilares de ápices caulinares adultos de Vaccinium meridionale; probablemente, la concentración de algunas sales presentes en estos medios, así como su interacción con la citoquinina, crean un ambiente inhibitorio para la reactivación de las yemas. Las yemas inhibidas sufrieron procesos necróticos y murieron; observaciones similares fueron reportadas por Morley et al. (1992) en Vaccinium corymbosum, especie en la que observaron pardeamiento y necrosis marginal en hojas adultas cuando fueron cultivadas en medios con bajos niveles de sales; mientras que al incrementar dichos niveles ocurrieron los mismos procesos pero en hojas jóvenes. Además, Ballinger (1962) indicó que en Vaccinium corymbosum no existe un mecanismo de exclusión de sales cuando se alcanzan niveles tóxicos; esta apreciación fue confirmada por Morley et al. (1992). Por su parte Debnath \& McRae (2001), en trabajos con Vaccinium vitis-idaea utilizaron WPM suplementado con 2-iP y cuantificaron una baja tasa de multiplicación de brotes en comparación con la cuantificada en MS; mientras que González et al. (2000) establecieron exitosamente cultivos in vitro de Vaccinium corymbosum a partir de segmentos nodales, en medio WPM con $25 \mathrm{mM}$ de 2-iP. Reed \& Abdelnour (1991) utilizaron WPM modificado suplementado con zeatina $(18,24 \mu \mathrm{M})$ y establecieron in vitro ápices caulinares de Vaccinium corymbosum. Además, Kyte (1987) para Rhododendron spp, y Ostrolucká et al. (2007) para Vaccinium corymbosum utilizaron el medio de Anderson (MS modificado) para el desarrollo de explantes y reportaron que es factible obtener de 3 a 4 hojas por explante después de 6 semanas y 10,16 a 15,23 brotes de Vaccinium corymbosum en medio suplementado con $9,12 \mu \mathrm{M}$ de zeatina.

En los ensayos para establecimiento de explantes realizados en este trabajo, la reactivación y desarrollo de yemas axilares fue más efectiva en explantes cultivados en $\mathrm{MS} / 3$ suplementado con 2-iP más AIA; este medio contiene una menor concentración de sulfato de magnesio con respecto 
a la concentración en AND y WPM. Además, en MS/3 con 2-iP se cuantificó mayor número de yemas reactivadas que en $\mathrm{MS} / 3$ con $\mathrm{BA}$, mientras que en el medio propuesto por Kyte, el número de yemas reactivadas fue mayor con $\mathrm{BA}$ que con 2-iP. En WPM y Anderson el 2-iP inhibió la reactivación de yemas, mientras que el BA si estimuló dicha reactivación. Estas observaciones indican que no solo la composición del medio de cultivo afecta el desarrollo de yemas, sino que, además, tanto el tipo de citoquinina, como la concentración, interactúan afectando de manera directa la inducción de crecimiento y desarrollo de yemas axilares en explantes de Vaccinium meridionale. En este contexto, Ostrolucká et al. (2007) afirman que la capacidad de regeneración de los tejidos es altamente dependiente del cultivar, el tipo de citoquinina y la concentración utilizada, para la regeneración de brotes de Vaccinium corymbosum.

Con respecto a procesos de proliferación, en diferentes especies de Vaccinium se ha utilizado con éxito el 2-iP a concentraciones elevadas. En este trabajo, 59,05 $\mu \mathrm{M}$ de 2-iP fue una concentración efectiva para reactivación y proliferación de yemas axilares; Marcotrigiano \& McGlew (1991) sugirieron que altos niveles de esta fitohormona son óptimos para proliferación de brotes de Vaccinium macrocarpon y, Pereira (2006) obtuvo un incremento en el número de brotes por explante en Vaccinium cylindraceum a medida que incrementó la concentración de 2-iP $(0-73,8$ $\mu \mathrm{M})$. Así mismo, para explantes de Vaccinium myrtillus una concentración de 49,2 $\mu \mathrm{M}$ de 2-iP fue más efectiva para iniciar el crecimiento, aunque para explantes de Vaccinium vitis-idaea fueron favorables concentraciones más bajas $(9,8-24,6 \mu \mathrm{M})$ de 2-iP (Jaakola et al. 2001). Marcotrigiano \& McGlew (1991) y Smagula \& Harker (1997) también sugirieron utilizar altos niveles de 2-iP para proliferación in vitro de brotes de Vaccinium macrocarpon, de igual manera que Nickerson (1978), Frett \& Smagula (1983) y Brisette et al. 1990, citados por Debnath \& McRae (2001) para Vaccinium. angustifolium y Zimmerman \& Broome $(1979 ; 1980)$ para Vaccinium corymbosum L. Sin embargo, Jaakola et al. (2001) indican que al combinar el 2-iP con una auxina se puede presentar desarrollo de callos, pardeamiento y muerte posterior del explante; estas indicaciones no concuerdan con lo observado en este trabajo puesto que la citoquinina siempre se adicionó a los medios de cultivo combinada con una auxina y los explantes no formaron callo.

Los ciclos de proliferación de Vaccinium meridionale tardaron entre 6 y 9 semanas de cultivo; datos similares fueron obtenidos por Jaakola et al. (2001), quienes determinaron que para la multiplicación de explantes de Vaccinium myrtillus y Vaccinium vitis-idaea, usualmente son necesarias 5 a 8 semanas de cultivo.

La concentración de 2-iP utilizada en este trabajo, $59,05 \mu \mathrm{M}$, inhibió la elongación de los brotes de Vaccinium meridionale. Datos similares, producción de brotes cortos con pocas hojas, fueron reportados por Debnath \& McRae (2001) en Vaccinium macrocarpon, cuando utilizaron concentraciones elevadas de 2-iP $(>49,21 \mu \mathrm{M})$. Pereira (2006) en Vaccinium cylindraceum observó aumento del número de brotes regenerados, pero disminución tanto del número de nudos por brote como en la longitud de los brotes regenerados, cuando las concentraciones de 2-iP incrementaron de 12,3 a 73,8 $\mu \mathrm{M}$. Debnath \& McRae (2001), reportaron que altas concentraciones de esta fitohormona inhiben la elongación de brotes en cultivos de Vaccinium macrocarpon. Debnath (2003) en ensayos con N-fenil N’-1,2,3-tidiazol-5-il úrea (TDZ) y Zeatina obtuvo un incremento en el número de yemas adventicias pero sin elongación, concluyendo que las citoquininas comúnmente estimulan la proliferación de brotes e inhiben su elongación. En este trabajo se observó que los microtallos de Vaccinium meridionale elongaron cuando se cultivaron en $\mathrm{MS} / 3$ suplementado con $3 \mathrm{~g} \cdot \mathrm{L}^{-1}$ de carbón activado. Además, se observó que en medio sin reguladores de crecimiento la elongación de los microtallos fue escasa, contrastando con los datos obtenidos en Vaccinium macrocarpon, Qu et al. (2000) y Vaccinium corymbosum, Cao \& Hammerschlag (2000) en los cuales los brotes adventicios regenerados a partir de explantes de hoja elongaron en medio basal libre de reguladores de crecimiento.

La inducción de enraizamiento de microtallos de $1,5 \mathrm{~cm}$ de longitud mediante la aplicación de pulsos de 2 minutos, con 4,90 y 29,52 $\mu \mathrm{M}$ de AIB, no tuvo éxito; probablemente, esta respuesta está influenciada por la longitud de los microtallos, la concentración de la auxina, el tiempo de exposición y la especie utilizada para este ensayo. Ostrolucká et al. (2007), utilizando brotes de Vaccinium corymbosum de 15-20 cm y tratándolos con una solución de 3,94 $\mu \mathrm{M}$ de AIB durante 2-3 minutos, obtuvieron $80 \%$ de enraizamiento; Debnath $(2003 ; 2005)$ utilizó brotes de Vaccinium vitis-idaea de 2-3 y 3-4 cm de longitud y los trató con una solución de $39,4 \mathrm{mM}$ de AIB y 80 a $90 \%$ de los brotes enraizaron después de 4 semanas de cultivo en turba-perlita, 2:1. Jaakola et al. (2001) utilizó brotes de Vaccinium myrtillus y Vaccinium vitis-idaea de 3 a $5 \mathrm{~cm}$ de longitud $\mathrm{y}$, sin tratamiento hormonal ó con inmersión durante 5 minutos en una solución de 2,07 $\mathrm{mM}$ de AIB, obtuvo $80 \%$ de enraizamiento.

De manera evidente, para Vaccinium meridionale, la inducción in vitro de enraizamiento de microtallos fue más favorable que la inducción mediante pulsos con soluciones de AIB (Tab. 6 y 7). Aunque las concentraciones de AIB utilizadas para inducir enraizamiento in vitro fueron altas no inhibieron el desarrollo radical, alcanzándose cerca de $90 \%$ de microtallos enraizados cuando, después del periodo de inducción, se transfirieron a tierra de capote. Porcentajes similares de enraizamiento se cuantificaron cuando microtallos elongados en medio con carbón activado se transfirieron al mismo sustrato. Estos resultados difieren de los obtenidos por Ostrolucká et al. (2007) quienes cuantificaron $80-95 \%$ de enraizamiento in vitro en medio AND suplementado con $3,94 \mu \mathrm{M}$ de AIB y $0,8 \mathrm{~g} \cdot \mathrm{L}^{-1}$ de carbón activado y, con los obtenidos por Jaakola et al. (2001), 
quienes cultivaron brotes Vaccinium myrtillus y Vaccinium vitis-idaea en medio MS con $0,49 \mu \mathrm{M}$ de IBA y obtuvieron $81,3 \%$ de enraizamiento.

Los altos porcentajes ( 88 y $90 \%$ ) de microtallos que enraizaron en medio sin reguladores y suplementado con 3 $\mathrm{g} \cdot \mathrm{L}^{-1}$ de carbón activado, respectivamente, indican que es posible suprimir el uso de auxinas para inducir rizogénesis en Vaccinium meridionale. Datos similares fueron reportados por Debnath \& McRae (2001) quienes utilizaron brotes de Vaccinium macrocarpon de 1-1,5 cm de longitud, los cultivaron en medio sin reguladores de crecimiento y obtuvieron $95-100 \%$ de brotes enraizados después de 4 semanas de cultivo. Así mismo, Shibli \& Smith (1996) alcanzaron $40 \%$ de microtallos de Vaccinium myrtillus enraizados en medio libre de reguladores de crecimiento y Pereira (2006) en Vaccinium cylindraceum obtuvo 21,3\% de brotes enraizados en medio libre de reguladores de crecimiento después de 12 semanas.

El desarrollo de un sistema radical vigoroso en tierra de capote durante la etapa de aclimatización, favoreció la obtención de plántulas con crecimiento activo y que soportan exitosamente el estrés producido por las condiciones propias del proceso de endurecimiento. Debnath (2003) y Debnath \& McRae (2001) consiguieron aclimatizar plantas de Vaccinium vitis idaea y de Vaccinium macrocarpon utilizando cubetas que colocaron en una cámara húmeda con un vaporizador $\left(22 \pm 2^{\circ} \mathrm{C}\right.$, humedad $95 \%, \mathrm{PPF}=55$ umolm $^{-2} \mathrm{~s}^{1}, 16$ horas de fotoperiodo); el proceso lo realizaron disminuyendo gradualmente la humedad durante 2-3 semanas en condiciones de invernadero.

En lo relacionado con la viabilidad de las plántulas obtenidas, en este trabajo se alcanzó $88-100 \%$ de plántulas viables después de la etapa de endurecimiento, cuando el enraizamiento de microtallos se indujo in vitro; además, se observó que aunque la apariencia de las plántulas fue normal, inicialmente su tasa de crecimiento es baja, requiriéndose 3 a 4 meses para obtener plántulas endurecidas de 20 a $30 \mathrm{~cm}$ de longitud (Fig. 2J3). Porcentajes semejantes, $80-90 \%$ de plantas endurecidas en cubetas con turba y perlita 2:1 (v/v), fueron obtenidos por Ostrolucká et al. (2007).

\section{Agradecimientos}

Los autores del trabajo expresan sus agradecimientos a la Universidad Pedagógica y Tecnológica de Colombia-Dirección de Investigaciones y al Gobierno Municipal de Tinjacá-Boyacá (Colombia) por el apoyo financiero para el desarrollo de esta investigación. Así mismo agradecen al profesor Alfonso Jiménez por la traducción al portugués y a los integrantes del Grupo de Investigación BIOPLASMA-UPTC por su continua colaboración.

\section{Referencias bibliográficas}

Anderson, W.C. 1984. A revised tissue culture medium for shoot multiplication of Rhododendron. Journal of American Society for Horticultural Science 109: 343-347.

Arjona, B. 2001. El mortiño o agraz (Vaccinium meridionale, Ericacea): como planta promisoria en la región del Parque Arví (Antioquia, Colombia). In: Seminario de Plantas Promisorias, Facultad de Agronomía, Universidad Nacional, Seccional Medellín.
Ávila, H.; Cuspoca, J.; Fischer, G.; Ligarreto, G. \& Quicazán, M. 2007. Caracterización fisicoquímica y organoléptica del fruto de agraz (Vaccinium meridionale Sw) almacenado 1 a $2{ }^{\circ} \mathrm{C}$. Revista Facultad Nacional de Agronomía 60(2): 4179-4193.

Ballinger, W.E. 1962. Studies of sulfate and chloride ion effects upon Wolcott blueberry growth and composition. Proceedings of American Society for Horticultural Science 80: 331-339.

Baskin, C.; Milberg, P.; Andersson, L. \& Baskin, J. 2000. Germination studies of three dwarf shrubs (Vaccinium, Ericaceae) of northern hemisphere coniferous forests. Revue Canadienne Journal Botanique 78(12): 1552-1560.

Brisette, L.; Tremblay, L. \& Lord, D. 1990. Micropropagation of lowbush blueberry from mature field-grown plants. Horticultural Science 25: 349-351.

Cao, X. \& Hammerschlag, F.A. 2000. Improved shoot organogenesis from leaf explants of highbush blueberry. Horticultural Science 35: 945-947.

Debnath, S. 2003. Improved shoot organogenesis from hypocotyl segments of lingonberry (Vaccinium vitis-idaea L.). In Vitro Cellular \& Developmental Biology-Plant 39: 490-495.

Debnath, S. 2005. Effects of carbon source and concentration on development of lingonberry (Vaccinium vitis - idaea L.) shoots cultivated in vitro from nodal explants. In Vitro Cellular \& Developmental Biology-Plant 41: 145-150.

Debnath, S. \& McRae, K. 2001. An efficient in vitro shoot propagation of Cranberry (Vaccinium macrocarpon Ait.) by axillary bud proliferation. In Vitro Cellular \& Developmental Biology-Plant 37: 243-249.

Echeverri, A. 2003. Conozcamos y Usemos el Mortiño. Medellín, CORANTIOQUIA.

Frett, J. \& Smagula, J. 1983. In vitro shoot production of lowbush blueberry. Canadian Journal Plant Science 63: 467-472.

González, M.; López, M.; Valdes, E. \& Ordas, J. 2000. Micropropagation of three berry fruit species using nodal segments from field-grown plants. Annals of Applied Biology 137(1): 73-78.

Jaakola, L.; Tolvanen, A.; Laine, K. \& Hohtola, A. 2001. Effect of $\mathrm{N}^{6}$ -isopentenyladenine concentration on growth initiation in vitro and rooting of bilberry and lingonberry microshoots. Plant Cell, Tissue and Organ Culture 66: 73-77.

Kyte, L. 1987. Plants from test tubes. An introduction to micropropagation. Hong Kong, Timber Press, Inc.

León, A. 2001. Cultivo de arándanos: Blueberries. Guía Frutihortícola. Santiago de Chile, Libreria Santa Fe - Fundación Chile.

Lloyd, G. \& Brent, McC. 1980. Commercially feasible micropropagation of mountain laurel, Kalmia latifolia, by use of shoot-tip culture. Proceedings International Plant Propagators' Society 30: 421-427.

Magnitskiy, S.V. \& Ligarreto, G.A. 2007. El efecto del nitrato de potasio, del ácido giberélico y del ácido indolacético sobre la germinación de semillas de agraz (Vaccinium meridionale Swartz). Revista Colombiana de Ciencias Hortícolas 1(2): 137-141.

Marcotrigiano, M. \& McGlew, S. 1991. A two-stage micropropagation system for cranberries. Journal of the American Society for Horticultural Science 116: 911-916.

Morley, S.M.; Stephen, F.C. \& Reinhard, F.M. 1992. Effects of $\mathrm{Na}_{2} \mathrm{SO}_{4}$, $\mathrm{K}_{2} \mathrm{SO}_{4}$ and $\mathrm{KCl}$ on growth and ion uptake of callus cultures of Vaccinium corymbosum L. cv. Blue Crop. Annals of Botany 69: 459-465.

Murashige, T. \& Skoog, F. 1962. A revised medium for rapid growth and bioassays with tobacco tissue cultures. Physiologia Plantarum 15: 437-497.

Nickerson, N. 1978. In vitro shoot formation in lowbush blueberry seedling explants. Horticultural Science 13: 698.

Ostrolucká, M.G.; Gajdošová, A.; Libiaková, G.; Hrubíková, K. y Bežo. 2007. Protocol for micropropagation of selected Vaccinium spp. Pp. 445-455. In: Jain, S.M. \& Häggman, H. (eds). Protocols for micropropagation of woody trees and fruits. Dordrescht, Springer.

Pereira, M.J. 2006. Conservation of Vaccinium cylindraceum Smith (Ericaceae) by micropropagation using seedling nodal explants. In Vitro Cellular \& Developmental Biology-Plant 42: 65-68.

Qu, L.; Polashock, J. \& Vorsa, N. 2000. A high efficient in vitro cranberry regeneration system using leaf explants. Horticultural Science 35: 948-952. 
Reed, B.M. \& Abdelnour, E.A. 1991. The use of zeatin to initiate in vitro cultures of Vaccinium species and cultivars. Horticultural Science 26: 1320-1322.

Shibli, R.A. \& Smith, M. 1996. Direct shoot regeneration from Vaccinium pahlae (Othelo) and V. myrtillus (bilberry) leaf explants. Horticultural Science 31: 1225-1228.

Smagula, J.M. \& Harker, J. 1997. Cranberry micropropagation using a lowbush blueberry medium. Acta Horticulturae 446: 343-347.

Trippi, V.S. 1982. Ontogenia y senilidad en plantas. Córdoba. Universidad Nac. Córdoba.

Valencia, M. 1993. Notas sobre la morfología, anatomía y germinación del agraz (Vaccinium meridionale $S w$ ). Agronomía Colombiana 10(2): 151-159.

Valencia, M. \& Becerra, N. 1995. Anatomía del fruto del agraz (Vaccinium meridionale Sw). Acta Biológica Colombiana 9: 159-172.
Vallejo, D.A. 2000. Fomento al mortiño (Vaccinium meridionale Sw): como especie promisoria del Parque Regional Arví. Medellín: CORANTIOQUIA

Viseur, J. 1987. Micropropagation of pear, Pyrus communis L., in a doublephase culture medium. Acta Horticulturae 212: 117-124.

Warnert, J. 1999. Growing blueberry frustrates farmes, but open doors. California Agriculture 53(6): 10.

Zimmerman, R.H. \& Broome, O.C. 1979. Propagation of blueberries through tissue culture. Horticultural Science 14: 477.

Zimmerman, R.H. \& Broome, O.C. 1980. Blueberry micropropagation. Proc. Conf. on Nursery Prod. of Fruit Plants through Tiss. Cult. Applications and Feasibility, U.S. Dep. Agric. Sci. and Ed. Adm. ARR-NE. 11: 44-47.

Versão eletrônica do artigo em www.scielo.br/abb e http://www.botanica.org.br/acta/ojs 